$16^{\circ}$ USIHC - Congresso Internacional de Ergonomia e Usabilidade de Interfaces Humano Computador

\title{
SISTEMAS DE CORES TÁTEIS: ESTUDO COMPARATIVO DE SUAS VANTAGENS E LIMITAÇÕES PARA PESSOAS COM DEFICIÊNCIA
}

\section{TACTILE COLOR SYSTEMS: COMPARATIVE STUDY OF ADVANTAGES AND LIMITATIONS FOR BLIND PEOPLE}

\author{
Tainá Apoena Bueno de Oliveira ${ }^{1}$, Esp. \\ Elton Moura Nickel ${ }^{2}$, Dr. Eng. \\ Milton José Cinelli, Dr. Eng.
(1) Universidade do Estado de Santa Catarina/UDESC e-mail: tainabueno@gmail.com \\ (2) Universidade do Estado de Santa Catarina/UDESC \\ e-mail: autor2@xxxyy.com.br \\ (3) Universidade do Estado de Santa Catarina/UDESC \\ e-mail: milton.cinelli@udesc.br
}

\section{Código tátil, Sistema de Cores, Deficiência Visual}

O presente artigo buscou comparar sistemas de cores para pessoas com deficiência visual e demonstrar as vantagens ou limitações de cada um. Foram analisados os sistemas Feelipa, Minardi, Vankrinkelveldt, Baklanov e Anczurowski. Todos os sistemas analisados apresentam características semelhantes, no entanto, Minardi se mostra mais completo e de fácil aprendizagem.

Tactile Code, Colors System, Blind People

The present article sought to compare color systems for the visually impaired and to demonstrate the advantages or limitations of each. The systems Feelipa, Minardi, Vankrinkelveldt, Baklanov and Anczurowski were analyzed. All systems analyzed have similar characteristics, however, Minardi is more complete and easy to learn.

\section{Introdução}

A deficiência visual é um tipo de deficiência sensorial que compromete a aquisição de informação por meio da visão, já que os canais sensoriais afetados são os da visão. Para suprir essa necessidade de se relacionar com o mundo
Realização:

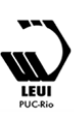




\section{$16^{\circ}$ \\ ERGODESIGN USIHC CINAHPA}

exterior, pessoas cegas utilizam estímulos sensoriais não visuais, como o toque e a audição. Para Ochaita e Rosa (1995, p.1), "a carência ou a séria diminuição da captação da informação, por um canal sensorial da importância da visão, faz com que a percepção da realidade de um cego seja muito diferente da dos que enxergam. Boa parte da categorização da realidade reside em propriedades visuais que se tornam inacessíveis ao cego, mas isto não quer dizer que careça de possibilidades para conhecer o mundo ou para representá-lo; o que ocorre é que, para isto, deve potencializar a utilização dos outros sistemas sensoriais. Dois sentidos mostram-se, então, como especialmente importantes: o ouvido e o sistema háptico. $\mathrm{O}$ primeiro deles adquire, no cego, funções telereceptoras de grande importância, [...]. O tato, por sua vez, é o sentido que permite ao cego o conhecimento sensorial dos objetos animados e inanimados que constituem o ambiente".

Neste momento, a pesquisa terá como foco o tato, embora cada sentido do corpo humano apresente possibilidades informativas distintas ajudando no processo de leitura e escrita. O tato vai além do conhecimento de objetos animados e inanimados. Uma de suas maiores funções está relacionada à alfabetização e à compreensão do mundo exterior por meio da leitura e escrita. Embora hoje em dia existam outros meios de aprendizado devido ao advento da tecnologia, a base está relacionada sempre à dinâmica da alfabetização por meio do tato, ainda que leitores de áudio facilitem este processo. Para Ochaita e Rosa (1995, p.1), a imagem da realidade que o cego percebe é diferente de um indivíduo vidente, ainda que esta maneira não deva ser considera melhor ou pior, afinal cada estímulo sensorial vivido por um indivíduo - seja este estímulo auditivo, visual ou tátil - corresponde a uma estrutura anatômica de receptores sensoriais diferentes, e o desenvolvimento de suas habilidades perceptivas lhe são correspondentes também. Muito além do desenvolvimento do sentido tátil na forma biomecânica, deve-se ressaltar que este está intimamente ligado ao desenvolvimento psicológico, sendo assim, as habilidades cognitivas desenvolvidas por pessoas com deficiência visual podem não ser coincidentes às de um individuo $16^{\circ}$ Ergodesign - Congresso Internacional de Ergonomia e Usabilidade de Interfaces Humano Tecnológica: Produto, Informações Ambientes Construídos e Transporte

$16^{\circ}$ USIHC - Congresso Internacional de Ergonomia e Usabilidade de Interfaces Humano Computador

CINAHPA | 2017 - Congresso Internacional de Ambientes Hipermídia para Aprendizagem.

vidente.

\section{Sistema Háptico ou Tato}

O sistema háptico ou tato é considerado o sistema preservado mais importante para uma pessoa com deficiência visual e está intimamente ligado a estímulos sensoriais. É preciso diferenciar o tato passivo e ativo, sendo o primeiro a informação tátil recebida de forma não intencional, e o ativo na busca intencional pela informação por meio do toque (GIBSON, 1966). Por meio do toque ativo, muitas propriedades do ambiente adjacente podem ser percebidas na ausência de visão (GIBSON, 1962, p.477).

A questão da aquisição de conceitos ou conhecimento por cegos é referente a qualquer pessoa, com ou sem alterações sensoriais (BATISTA, 2005, p.10). Na percepção e processamento da informação mediante o tato e a visão, existem importantes diferenças: a captação da informação mediante o tato é muito mais lenta que a proporcionada pelo sistema visual, o que traz consigo uma explicação de caráter sequencial e que gera uma maior carga na memória de trabalho. $\mathrm{O}$ tato constitui um sistema sensorial que tem determinadas características e que permite captar diferentes propriedades dos objetos, tais como temperatura, textura, forma e relações espaciais (OCHAITA; ROSA, 1995, p.1). A textura parece ter, para o tato, uma saliência perceptiva semelhante à da cor para a visão (WARREN, 1984 apud OCHAITA; ROSA, 1995, p.1). Dessa forma, as diferenças de textura são captadas pelo tato muito precocemente. Sendo assim, Ochaita e Rosa conclui que a respeito do desenvolvimento da percepção da forma dos objetos por meio do tato, os diferentes autores coincidem ao apontar que o movimento ou a atividade perceptiva autodirigida aumenta com a idade, o que torna possível um melhor reconhecimento dessas formas.

\section{Cores e Formas}

A cor, segundo Minardi (1994, p.3), “[...] é amplamente utilizada dentro da nossa linguagem 


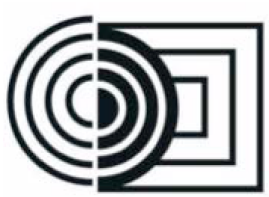

$16^{\circ}$ Ergodesign - Congresso Internacional de Ergonomia e Usabilidade de Interfaces Humano Tecnológica: Produto, Informações Ambientes Construídos e Transporte

$16^{\circ}$ USIHC - Congresso Internacional de Ergonomia e Usabilidade de Interfaces Humano Computador

CINAHPA | 2017 - Congresso Internacional de Ambientes Hipermídia para Aprendizagem. como meio de comunicar não apenas as cores dos objetos, mas também como codificação em mapas, gráficos e outras exibições visuais. A cor é um aspecto importante na comunicação para e com cegos ou deficientes visuais. Existe uma necessidade de símbolos unitários simples que podem ser aplicados em tudo, desde mapas até vestuário. Existe também a necessidade de símbolos que possam ser gravados em fotografias para proporcionar contorno, forma e cor aos elementos ilustrados".

Para Anczurowski (1987, p.1), a cor é um fator importante na comunicação entre videntes, usada em diversas áreas como em mapas, em desenhos da engenharia e em figuras geométricas usadas na estatística. Contudo, ainda não se tem uma técnica adequada, como o Braille é para o alfabeto, que facilite o reconhecimento de cor para um deficiente visual.

Segundo Thomazi (2014, p.85) as misturas podem ser aditivas, que é a cor percebida diretamente da fonte luminosa; e subtrativas, que é a cor percebida a partir do reflexo da luz sobre uma superfície e estas encontram-se na composição de cores RGB, CMY e RYB. O RGB é a síntese aditiva e conhecida como cor luz, o CMY (Cyan, Magenta e Yellow) é a síntese subtrativa da composição e conhecida como cor pigmento e o RYB (Red, Yellow e Blue) é a síntese subtrativa da arte e conhecida como cor pigmento. A RYB também é conhecida como cores primárias (figura 1), que são cores que existem sem a mistura de cores e não podem se decompor em outras. Logo, as cores secundárias são a união de duas cores primárias para a formação de uma nova cor. Já a união de uma cor primária e uma cor secundária para a formação de uma nova cor é conhecida como cores terciárias.

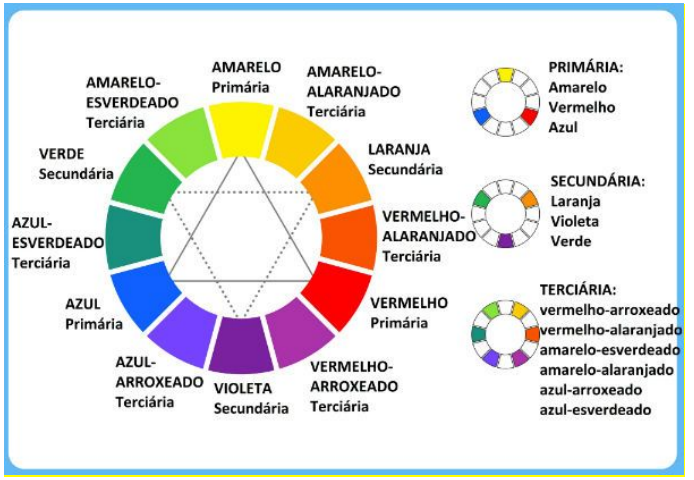

Figura 1 - Disco Cromático

Fonte: https://www.todamateria.com.br/cores-primarias/

Na Teoria das Formas, segundo o autor Gomes Filho (2009, p.17), a arte se funda no princípio da pregnância da forma, ou seja, na formação de imagens, os fatores de equilíbrio, clareza e harmonia visual são considerados indispensáveis. Para uma pessoa com deficiência visual, a harmonia visual de certa forma não seria tão importante, mas a clareza e a fácil percepção tátil sim. Segundo Kepes (1966, p.18), [...] o importante é perceber a forma por ela mesma, vê-la como "todos" estruturados, resultado de relações. Para Frutiger (2007, p.15), não há dúvida que a as associações entre formatos diferentes estimulam muito mais e de modo imediato impulsos estéticos.

$\mathrm{Na}$ escola de psicologia experimental, a Escola Gestalt, Christian von Ehrenfels iniciou, ainda no século XIX, os estudos a cerca da psicologia Gestalt. Mais tarde, em 1910, iniciaram os estudos na Universidade de Frankfurt por Max Wertheimer, Wolfgang Kohler e Kurt Koffka. Segundo Gomes Filho (2009, p.18), o movimento gestaltista atuou principalmente no campo da teoria da forma, com contribuição aos estudos da percepção, linguagem, inteligência, aprendizagem, memória, entre outros. Como leis básicas da Gestalt resultantes, estão: semelhança, proximidade, continuidade, pregnância, fechamento e unidade.

No Design Universal, estuda-se "Forma segue a função", segundo Lidwell, Holden e Butler (2010, p.106) há duas maneiras de se interpretar esta máxima: a primeira sendo "como descrição de beleza ou receita para beleza" e a segunda como "a beleza resulta na pureza da função e da ausência de ornamentação". Sendo a segunda, se limitando a 


\section{$16^{\circ}$ \\ ERGODESIGN USIHC CINAHPA}

considerar que a função deve ser mais importante que a estética. Ainda para os autores "os aspectos funcionais do design são menos subjetivos do que os estéticos e, assim, os critérios funcionais representam uma estética mais objetiva do que as alternativas".

Segundo o site Acessibilidade Brasil, hoje a reprodução de gráficos, desenhos ou imagens é feita por meio de texturas, que podem ser de forma manual ou digital com o auxílio do programa brasileiro Monet e uma legenda com o nome da cor e/ou da informação em Braille para identificar que aquela textura pode ser de alguma determinada cor. Este programa é compatível com o Braille Fácil, outro programa brasileiro, usado para textos. Ambos os programas estão disponíveis para download gratuitamente.

\section{Método}

O método utilizado para dar suporte ao desenvolvimento do estudo foi a revisão integrativa sistemática. Segundo Ferenhof e Fernandes (2016, p.1), esse tipo de revisão é uma investigação científica que visa eliminar vieses por meio do planejamento e sistematização de busca(s) em base de dados científicas por estudos originais, sintetizando os resultados em um portfólio bibliográfico. Foi, então, formulada a seguinte questão de pesquisa para este estudo: Quais estudos apresentavam soluções para representação de cores em meio tátil para pessoas com deficiência visual? Ou seja, será que existiam códigos de cores, como o Braille é para a leitura, que facilitassem o entendimento das cores e pudessem ser usados em diversos meios por uma pessoa com deficiência visual?

A partir da definição do tema a ser pesquisado, organizou-se o processo da revisão integrativa sistemática a partir das etapas de coleta de dados, análise de dados e síntese. Fora observado nas primeiras buscas que não se encontravam artigos científicos que fizessem menção à criação de um código de cores para pessoas com deficiência visual, porém, percebeu-se que existiam patentes $16^{\circ}$ Ergodesign - Congresso Internacional de Ergonomia e Usabilidade de Interfaces Humano Tecnológica: Produto, Informações Ambientes Construídos e Transporte

$16^{\circ}$ USIHC - Congresso Internacional de Ergonomia e Usabilidade de Interfaces Humano Computador

CINAHPA | 2017 - Congresso Internacional de Ambientes Hipermídia para Aprendizagem.

que mencionavam estes códigos. Então, na primeira parte do estudo, fez-se a identificação dos critérios de seleção e exclusão, determinando as palavras chave e os termos de pesquisa que seriam utilizados. Como critério de seleção, era necessário que as patentes apresentassem alguns destes itens:

- Apresentem soluções para várias cores, inclusive com a possibilidade de combinação de cores;

- Possam ser usados na aplicação em vários meios físicos como, por ex. vestuário.

E para critérios de exclusão, era necessário que as patentes não apresentassem estes itens:

- Não tenha relação com display, computador ou sistemas eletrônicos;

- Não tenha relação com o alfabeto;

As palavras chaves deveriam permitir a busca do tema proposto, por isso, foram selecionadas: color, code, tactile, blind e patent. De forma que elas obedecessem a seguinte query: color AND code AND blind AND tactile symbols AND patent. A pesquisa foi realizada no dia 20 de fevereiro e fora definido que não teria data pré-estabelecida e a busca realizada no Google Patents. Na busca foram encontradas 654 patentes, não se conseguiu diminuir este número pela limitação nos operadores lógicos Booleanos do Google Patents. Para a seleção dos artigos que interessavam o escopo da pesquisa, usaram-se os parâmetros de inclusão e exclusão previamente definidos e a criação de três filtros que serviriam para conhecer o conteúdo dos artigos a serem analisados. Estes filtros foram: (a) a leitura do título da patente, (b) a leitura do resumo, (c) a leitura completa da patente. Além da busca inicial com a query, também se utilizou as citações de pesquisas encontradas em patentes faziam pesquisas parecidas. Das patentes encontradas, cinco foram selecionadas para análise, entre elas Colour code for visually impaired people, Tactile symbols for color recognition, Tactile symbols for colour recognition by blind or visually impaired persons, Tactile Relief Films, Decals and Stickers for Indicating 


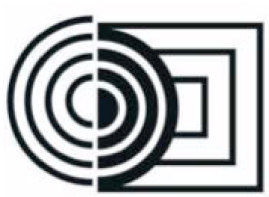

$16^{\circ}$ Ergodesign - Congresso Internacional de Ergonomia e Usabilidade de Interfaces Humano Tecnológica: Produto, Informações Ambientes Construídos e Transporte

$16^{\circ}$ USIHC - Congresso Internacional de Ergonomia e Usabilidade de Interfaces Humano Computador

CINAHPA | 2017 - Congresso Internacional de Ambientes Hipermídia para Aprendizagem.
Object Characteristics e Representation of Color for Blind Persons. Outras patentes que interessavam a pesquisa foram descartadas por não apresentarem imagens de como funcionavam os sistemas para a análise, são elas Colour-code marking of itens, Method for Simulation of Colours and Associated Articles for Blind e Method for Producing a Printed Product with Representation of a Graphic Object that is Perceptible to the Blind $r$ Partially Sighted by Touch, and Printed Product Produced by this Method.

Nas patentes, descobriu-se a denominação por classe. No caso da pesquisa, foram utilizadas patentes que pertenciam as classes G09B21/003 Teaching or communicating with blind persons using tactile presentation of the information, e.g. Braille displays e também G09B19/0023 Colour matching, recognition, analysis, mixture or the like.

O propósito deste artigo foi, então, avaliar de forma sistemática patentes de sistemas de cores que podem ser uma alternativa viável ao Braille para o reconhecimento de cor em diversos meios.

\section{Sistema de Cores}

\subsection{Feelipa}

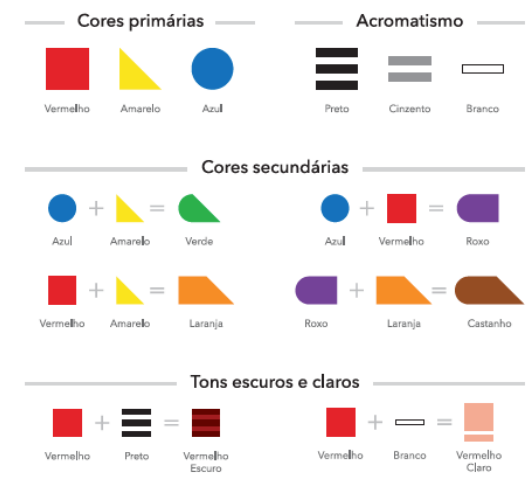

Figura 2 - Colour code for visually impaired people

Fonte: www.feelipa.com
O Feelipa (figura 2) é um sistema de cores, no qual a sua patente foi requerida em 2013. O resumo do documento Colour code for visually impaired people (WO $2013137757 \mathrm{~A} 1$ ) apresenta as seguintes informações acerca do sistema: O código de cores para pessoas com deficiência visual que foi desenvolvido para auxiliar os deficientes visuais, seja totalmente cego, com visão subnormal, cego ou com qualquer outra incapacidade ou limitações relacionadas aos olhos, consistindo de um processo de compreensão e reconhecimento de cores por meio da associação simples de formas geométricas universais. Estas formas podem ser aplicadas em quase todos os materiais, aumentando assim a autonomia das pessoas com deficiência visual. Suas principais características são a memorização fácil e o reconhecimento sem esforço das formas que, agregadas de acordo com um raciocínio lógico e simples, assim como a associação de cores na Síntese Aditiva da Cor, são sempre apresentadas em alto relevo, para permitir melhor reconhecimento tátil. A grande vantagem desta invenção é que torna possível o reconhecimento de cores e seus respectivos tons em qualquer lugar do mundo, por meio de sua correspondência com certas formas geométricas e linhas que podem ser adicionadas a eles.

\subsection{Minardi}
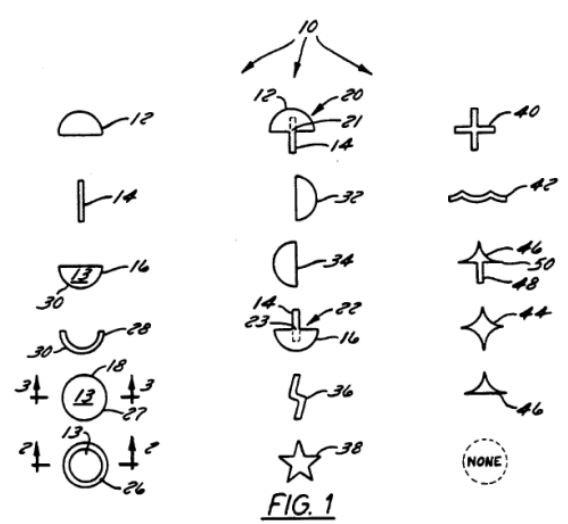

Figura 3 - Tactile symbols for color recognition

Fonte: Patente US 5286204 A 


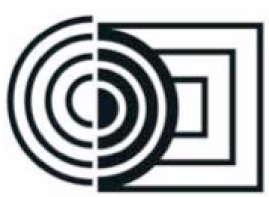

O Minardi (figura 3) é um sistema de cores no qual a sua patente foi requerida em 1994. O resumo do documento Tactile symbols for color recognition (US 5286204 A) apresenta as seguintes informações acerca do sistema: Símbolos táteis para o reconhecimento de cor por pessoas com deficiência visual compreendendo uma superfície acima da qual um símbolo de cor é elevado substancialmente paralelo à primeira superfície. A superfície elevada do símbolo unitário é contínua, de modo que as pessoas possam identificar o símbolo pelo toque.

\subsection{Vankrinkelveldt}

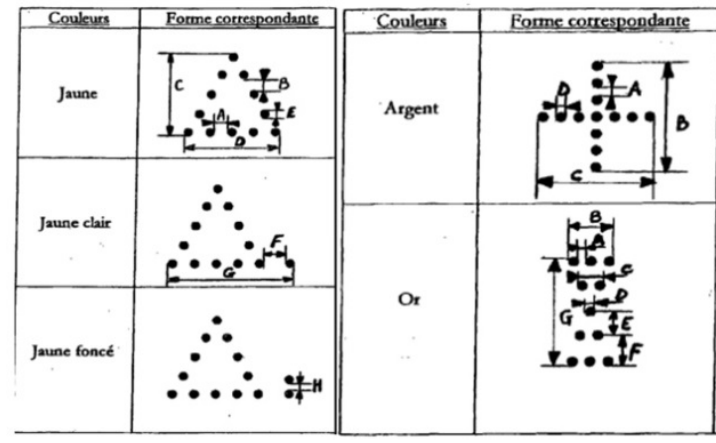

Figura 4 - Tactile symbols for colour recognition by blind or visually impaired persons Fonte: Patente EP 1318494 A1

O Vankrinkelveldt é um sistema de cores no qual a sua patente foi requerida em 2003. O resumo do documento Tactile symbols for colour recognition by blind or visually impaired persons (EP 1318494 A1) apresenta as seguintes informações acerca do sistema: A invenção refere-se a um método para aplicar uma forma geométrica num suporte, em que a referida forma é selecionada a partir de um conjunto de formas geométricas, cada um associado a uma única cor predeterminada e o alívio é aplicado sobre a referida apoiando um conjunto de sinais ocasionais constituindo a forma, para permitir a percepção tátil da cor associada com a forma.

\subsection{Baklanov}

$16^{\circ}$ Ergodesign - Congresso Internacional de Ergonomia e Usabilidade de Interfaces Humano Tecnológica: Produto, Informações Ambientes Construídos e Transporte

$16^{\circ}$ USIHC - Congresso Internacional de Ergonomia e Usabilidade de Interfaces Humano Computador

CINAHPA | 2017 - Congresso Internacional de Ambientes Hipermídia para Aprendizagem.

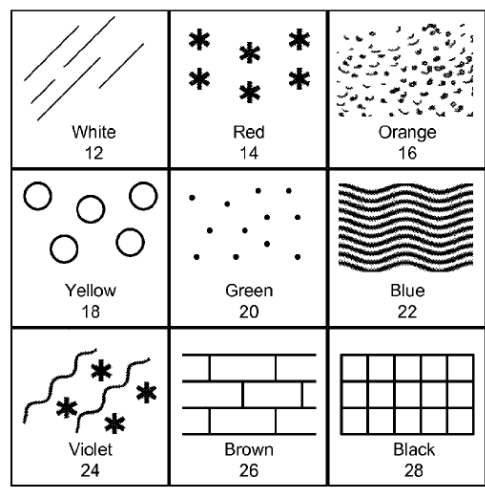

Figura 5 - Tactile Relief Films, Decals and Stickers for Indicating Object Characteristics

Fonte: Patente US 8672680 B2

O Baklanov é um sistema de cores no qual a sua patente foi requerida em 2014. O resumo do documento Tactile Relief Films, Decals and Stickers for Indicating Object Characteristics (US 8672680 B2) apresenta as seguintes informações acerca do sistema: É um sistema de etiquetas, decalques e/ou molde de relevo tátil para indicar as características em relação a cor do objeto. O sistema pode incluir uma pluralidade de adesivos. Cada adesivo pode ter uma primeira e uma segunda camada de textura, sendo a segunda oposta à primeira. Cada adesivo pode ter uma textura correspondente a uma cor de acordo com a correspondência predeterminada para uma cor. A segunda superfície pode ter um adesivo aplicado ao mesmo.

\subsection{Anczurowski}

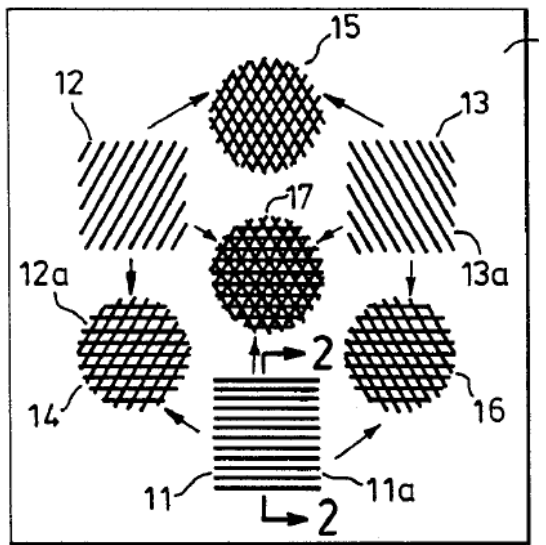

Realização:

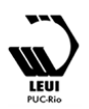




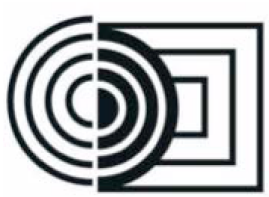

Figura 6 - Representation of Color for Blind Persons Fonte: Patente US 4650421

O Anczurowski é um sistema de cores no qual a sua patente foi requerida em 1987 . O resumo do documento Representation of Color for Blind Persons (US 4650421) apresenta as seguintes informações a cerca do sistema: $\mathrm{O}$ primeiro conjunto de linhas paralelas representa a primeira cor, um segundo conjunto de linhas paralelas orientadas numa segunda direção representa a segunda cor e um terceiro conjunto de linhas paralelas orientadas numa terceira direção representa a terceira cor. As três cores são diferentes entre si (magenta, ciano e amarelo) e, quando misturadas em combinações diferentes, fornecem outras cores (verde, roxo e vermelho), podendo ser derivado por várias combinações de duas das três cores básicas e preto em todos. As três direções são diferentes uma da outra, por exemplo, horizontal, $60^{\circ}$ e $120^{\circ}$.

\section{Análise e Discussão dos Resultados}

Em relação à simplicidade da forma, para Minardi (1994, p.3), "existe uma necessidade de símbolos unitários simples que podem ser aplicados em tudo, desde mapas até vestuário. Existe também a necessidade de símbolos que possam ser gravados em fotografias para proporcionar forma e cor aos elementos ilustrados".

\subsection{Funcionamento do Sistema}

O autores a seguir apresentam o funcionamento de cada sistema em texto corrido, porém, para fins didáticos, será apresentado na forma de itens ressaltando as principais características do sistema.

\section{Feelipa (2013)}

- $\mathbf{1}^{\mathbf{0}}$ conjunto: apresenta três formas geométricas básicas (círculo, quadrado e retângulo) que $16^{\circ}$ Ergodesign - Congresso Internacional de Ergonomia e Usabilidade de Interfaces Humano Tecnológica: Produto, Informações Ambientes Construídos e Transporte

$16^{\circ}$ USIHC - Congresso Internacional de Ergonomia e Usabilidade de Interfaces Humano Computador

CINAHPA | 2017 - Congresso Internacional de Ambientes Hipermídia para Aprendizagem.

representam cores primárias;

- $2^{\circ}$ conjunto: apresenta a combinação das três formas geométricas básicas que representam as cores primárias. Essas formas, quando misturadas entre si, formam as cores secundárias, apresentando três novas formas geométricas (pela junção) e um relevo que apresenta preenchimento total da forma;

- $3^{\circ}$ conjunto: apresenta solução para cores claras, normalmente criado pela mistura da cor com o branco, é formado pela figura referente à cor mais uma linha logo abaixo da forma geométrica;

- $4^{\circ}$ conjunto: apresenta solução para cores escuras, normalmente criado pela mistura da cor com o preto, é formado pela figura referente à cor mais três linhas em cima da forma geométrica;

- $5^{\circ}$ conjunto: apresenta três formas geométricas que representam cores acromáticas, são elas: preto, branco e cinza;

- Todas as formas apresentam relevo com preenchimento total da forma;

- A adição das formas geométricas se dá de maneira congruente;

- Para utilização por pessoas com deficiência visual, as formas geométricas devem ser gravadas de forma tridimensional e/ou alto-relevo;

- Por fim, o autor sugere a aplicação não apenas em imagens, mas em todo o resto que necessitar uma diferenciação ou explicação de cor (vestuário, papelaria, acessórios, etiquetas, mobiliário, sinalética, livros, entre outros).

\section{Minardi (1994)}

- $1^{0}$ conjunto: apresenta três formas geométricas que representam cores primárias e que o relevo apresenta preenchimento total da forma;

- $2^{\circ}$ conjunto: apresenta a combinação das três formas geométricas que representam as cores 
$16^{\circ}$ USIHC - Congresso Internacional de Ergonomia e Usabilidade de Interfaces Humano Computador

CINAHPA | 2017 - Congresso Internacional de Ambientes Hipermídia para Aprendizagem.

primárias que misturadas entre si formam as cores secundárias, apresentando quatro novas formas geométricas secundárias (pela junção das primárias) e o relevo apresenta preenchimento total da forma;

- $3^{\mathbf{0}}$ conjunto: apresenta solução para cores claras normalmente criado pela mistura da cor com o branco, é formado pela figura referente à cor, porém, o seu relevo apresenta apenas o preenchimento do contorno;

- $4^{\mathbf{o}}$ conjunto: apresenta oito formas geométricas que representam cores que o autor cita como complexas, são elas: marrom, magenta, prata, ouro, bronze, cor de água "water color", preto e cinza. $\mathrm{O}$ relevo apresenta preenchimento total da forma;

- A adição das formas geométrica se dá de forma congruente;

- As formas geométricas são invariante rotativamente;

- Para utilização por pessoas com deficiência visual, as formas geométricas devem ser gravadas de forma tridimensional e/ou alto-relevo;

- Se a imagem fornecer mais de uma cor, para categorizar, é necessário a utilização de uma linha em alto-relevo que faça o contorno em torno das cores para que seja compreendido os limites da referida cor;

- Qualquer área que não tenha formas geométricas é considerada branca;

- A matriz para a criação das formas geométricas foram as formas geométricas básicas (círculo, quadrado e pirâmide);

Por fim, o autor sugere a aplicação não apenas em imagens, mas em todo o resto que necessitar uma diferenciação ou explicação de cor (vestuário, imagens, entre outros).
- $\mathbf{1}^{\mathbf{0}}$ conjunto: apresenta diversas formas geométricas e cada uma é associada a uma cor predeterminada a fim de permitir uma percepção táctil da cor associada a referida forma;

- $2^{\circ}$ conjunto: apresenta formas geométricas que se formam pelo relevo de pontos, seguindo o mesmo conceito da escrita em Braille, com exceção das cores pretas e brancas que apresentam relevo em toda a sua forma;

- $3^{\circ}$ conjunto: apresenta solução para cores claras normalmente criado pela mistura da cor com o branco, é formado por um ponto alinhado ao ponto base na lateral direita da figura geométrica;

- $4^{0}$ conjunto: apresenta solução para cores escuras normalmente criado pela mistura da cor com o preto, é formado por dois pontos, um em cima do outro, alinhado ao ponto base na lateral direita da figura geométrica;

- $5^{\circ}$ conjunto: apresenta catorze formas geométricas associadas a cores;

- Para o autor, a utilização de uma única forma geométrica para indicar a cor reduz o espaço se comparado ao Braille;

- A associação com a forma facilita a leitura independente do idioma;

- Para o autor, é possível combinações de formas geométricas simples para formar outras formas geométricas originando novas cores, seguindo o esquema da matriz de cores;

- Para utilização por pessoas com deficiência visual, as formas geométricas devem ser gravadas de forma tridimensional e/ou alto-relevo;

- Por fim, o autor sugere a aplicação não apenas em imagens, mas em todo o resto que necessitar uma diferenciação ou explicação de cor (vestuário, imagens, desenho industrial, papelaria, entre outros).

\section{Vankrinkelveldt (2003)}


$16^{\circ}$ Ergodesign - Congresso Internacional de Ergonomia e Usabilidade de Interfaces Humano Tecnológica: Produto, Informações Ambientes Construídos e Transporte

$16^{\circ}$ USIHC - Congresso Internacional de Ergonomia e Usabilidade de Interfaces Humano Computador

CINAHPA | 2017 - Congresso Internacional de Ambientes Hipermídia para Aprendizagem.

Os adesivos táteis tornam possível o reconhecimento de cores, podendo ser aplicado em variados objetos. O material deve ser transparente para que uma pessoa vidente possa ver a cor e aplicados pós-produção não devendo interferir no funcionamento adequado do objeto. Deve ser maleável com uma camada autocolante.

- $\mathbf{1}^{\mathbf{0}}$ conjunto: Em relação ao mapeamento de cores, uma das primeiras indicações em relação à textura é que ela se pareça com o objeto a que está identificando. Se for a cor laranja que se deseja determinar, a textura será similar a de uma laranja;

- $2^{\circ}$ conjunto: a patente já define nove cores e estão representadas na figura 5 . As cores são $o$ branco, o vermelho, o laranja, o amarelo, o verde, o azul, o violeta, o marrom e o preto. Para o branco é usada a textura polida com relevo de linhas, símbolos na parte superior. Para o vermelho é usado pequenos asteriscos. Para o laranja, uma textura similar a da fruta laranja. Para o amarelo, círculos rebaixados. Para o verde, textura semelhante a pele de pepino. Para o azul, linhas onduladas e o espaçamento entre elas podendo indicar a matiz. Para o violeta, linhas onduladas intercaladas com asteriscos. Para o marrom, padrão de alvenaria e por fim, para o preto, textura de treliça;

- $3^{\mathbf{o}}$ conjunto: Para pessoas videntes, o adesivo tátil pode ser usado na identificação do objeto no escuro, usando materiais fosforescentes em sua produção;

- $4^{0}$ conjunto: a textura pode se apresentar de forma positiva (com relevo para cima) ou de forma negativa (com rebaixamento).

\section{Anczurowski (1987)}

O sistema apresenta a cor por sobreposição de dois ou mais conjuntos de linhas, para que sejam entendidas cores diferentes, apresentando-se de forma paralela entre si. A linha do primeiro sentindo apresenta uma cor e dos demais sentidos outras cores.
- $1^{0}$ conjunto: Cada cor primária é representada por um conjunto de linhas paralelas e os vários conjuntos estão orientados em ângulos diferentes um dos outros;

- $2^{\mathbf{0}}$ conjunto: As linhas possuem os ângulos $0^{\circ}$ representando a cor magenta, $60^{\circ}$ representando a cor ciano e $120^{\circ}$ representando a cor amarela. A combinação destas linhas formam outras cores, como por exemplo ciano e magenta $\left(0^{\circ}\right.$ e $\left.60^{\circ}\right)$ formando a cor roxa. Dessa mesma forma podem ser representadas outras cores (roxo, verde e vermelho);

- $3^{\mathbf{0}}$ conjunto: Para a representação da cor preta os três conjuntos de linhas devem estar sobrepostos uns aos outros.

\subsection{Análise e Discussão}

Para coleta de dados, a primeira etapa consistiu na decupagem dos sistemas de cores para analisar os aspectos mais importantes. Foram apresentados cinco sistemas, sendo eles: Feelipa, Minardi, Vankrinkelveldt, Baklanov e Anczurowski. Destes cinco sistemas, os que mais se assemelham são o Feelipa e Minardi. Embora Vankrinkelveldt apresente soluções geométricas como os outros, ele difere na criação de novas cores. Já os sistemas Baklanov e Anczurowski se diferem dos demais ao apresentarem texturas para diferenciar as cores. A seguir serão apresentados os sistemas conforme suas semelhanças, correlacionando-os entre si.

O sistema Feelipa apresenta as três formas básicas representando as cores primárias, assim como o Minardi. Na junção por combinação de duas formas primárias, cria-se uma nova forma e também uma nova cor, seguindo o mesmo modelo do círculo cromático, sendo cores primárias formando cores secundárias e uma cor primária com uma secundária formando uma cor terciária. $\mathrm{O}$ sistema Minardi apresenta, também, a solução para cores que não se obtém combinando as cores do círculo cromático, o autor apresenta oito formas geométricas que representam cores complexas. $\mathrm{O}$ sistema Vankrinkelveldt, apesar de também se

Realização:




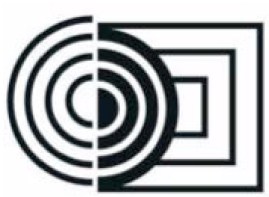

$16^{\circ}$ Ergodesign - Congresso Internacional de Ergonomia e Usabilidade de Interfaces Humano Tecnológica: Produto, Informações Ambientes Construídos e Transporte

$16^{\circ}$ USIHC - Congresso Internacional de Ergonomia e Usabilidade de Interfaces Humano Computador

CINAHPA | 2017 - Congresso Internacional de Ambientes Hipermídia para Aprendizagem. basear em formas geométricas, utiliza um sistema semelhante ao Braille, com a criação das formas básicas por meio de pontos. $\mathrm{O}$ autor apresenta também uma solução para cores complexas, porém a questão de união das formas para a criação de uma nova cor não se mostra muito clara. O sistema Feelipa não apresenta uma solução para essas cores complexas. O sistema Vankrinkelveldt e Feelipa apresentam uma solução para tons claros e escuros de uma mesma cor, no caso do Feelipa apresentando traços que podem vir por cima ou por baixo da cor, dependendo se ele será claro ou escuro, já no caso do sistema Vankrinkelveldt apresenta um ponto ou dois pontos dependendo se será claro ou escuro. O Minardi apresenta apenas a previsão de tons claros, mudando o tipo do relevo.

Em essência, o Feelipa apresenta relevo em todo o preenchimento da forma, o Minardi apresenta tanto preenchimento da forma como apenas relevo das bordas e o Vankrinkelveldt apresenta as formas geométricas por meio de um contorno de pontos.

Os sistemas Baklanov e Anczurowski apresentam soluções com diferentes tipos de relevo não correlacionando as cores a um objeto geométrico. O Anczurowski se assemelha aos demais sistemas geométricos, pois apresenta uma textura fixa para cada cor e, consequentemente, apresenta, a junção de texturas para a criação de uma nova cor. Contudo, diferente dos demais, esse sistema não deixa claro uma previsão para outras cores e para tons claros e escuros, podendo ser considerado um ponto falho. De todosos sistemas avaliados Baklanov é que se apresenta mais diferente, apesar de apresentar texturas como o Anczurowski, ele já tem pré-definidas nove cores que não necessariamente formam outras por meio de junção. Em relação às cores, o sistema tenta apresentar texturas semelhante à cor, como a cor laranja e a textura da fruta laranja. Como o Anczurowski, o sistema não apresenta previsão para outras cores e para tons claros ou escuros, além disso, uma vez que as cores são pré-definidas, o usuário terá que decorar todas as cores, podendo ser considerado um ponto falho junto as outras faltas que o sistema apresenta.

Segundo Gibson (1962, p.477) o toque ativo é um sentindo exploratório e o que acontece em seus dedos depende dos movimentos que ele faz e também, obviamente, do objeto que ele toca. Logo, eles aprimoram algumas características de estimulação e outras reduziram, sendo assim os movimentos dos dedos são parecidos com os movimentos dos olhos, podendo dizer que esse movimento é uma varredura tátil em analogia a varredura tátil.

Logo, para Gibson, o fato de haver uma intenção na hora de usar o sistema tátil já se facilita o processo de leitura e a identificação do que ali pode estar representando. Embora haja essa diferença de relevo das formas, acredita-se que todos funcionem para uma percepção tátil.

\section{Considerações Finais}

Todos os cinco sistemas apresentam uma solução para a caracterização da cor em diversos tipos de suportes que podem funcionar. Embora o Feelipa seja o mais novo deles, acredita-se que falta a previsão para cores mais complexas, porém suas formas são de boa pregnância e o sistema da união das formas facilita na hora de não precisar reconhecer uma nova forma geométrica que tenha características muito diferentes. Apesar do Minardi ser anterior, ele apresenta a solução tanto para as cores complexas e na união das formas, faltando uma previsão para cores escuras. E o Vankrinkelveldt, se comparado a esses dois sistemas anteriores, torna-se um pouco complexo devido à necessitadade da aprendizagem das formas geométricas de cada cor, porém, por ser próximo ao Braille, poderia facilitar a adaptação de uma pessoa com deficiência visual. Os últimos dois sistemas analisados apresentam, sim solução para identificação de cores, mas falhos se forem comparados aos outros sistemas que apresentam a geometria como princípio principal. O sistema Baklanov seria um bom sistema a ser melhorado, acredita-se que ele cumpre sua função, porém faltam detalhes que poderiam melhorá-lo, mas é um sistema com bom potencial.

O pesquisador sugere para pesquisas futuras um
Realização:

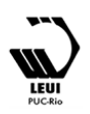




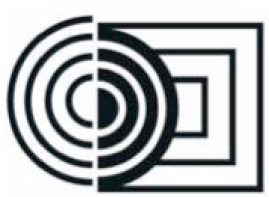

$16^{\circ}$ Ergodesign - Congresso Internacional de Ergonomia e Usabilidade de Interfaces Humano Tecnológica: Produto, Informações Ambientes Construídos e Transporte

$16^{\circ}$ USIHC - Congresso Internacional de Ergonomia e Usabilidade de Interfaces Humano Computador

CINAHPA | 2017 - Congresso Internacional de Ambientes Hipermídia para Aprendizagem. experimento com pessoas com deficiência visual, justamente para comprovar estas questões levantadas na comparação entre os sistemas e também para buscar perceber qual sistema seria melhor de acordo com a percepção do usuário. Como resultado parcial, acredita-se que ambos os sistemas funcionem bem, porém os que apresentam uma maior facilidade aparente de aprendizagem seriam o Feelipa, Minardi e Baklanov, sendo o Minardi um sistema que se mostra um pouco mais elaborado em relação aos demais, enquanto os sistemas Vankrinkelveldt e Anczurowski necessitariam de uma memorização maior por parte do usuário.

Acredita-se que esta pesquisa tenha gerado uma boa discussão para se determinar um sistema de cores que facilite a percepção das cores por pessoas com deficiência visual e também a possível autonomia na hora escolher produtos que se necessita saber a cor. Um sistema de cor poderia ter um melhor aproveitamento em relação ao que é usado agora com o Braille.

\section{BIBLIOGRAFIA}

ACESSIBILIDADE BRASIL. Instituto Benjamin Constant lança o programa MONET - gerador de gráficos táteis. Disponível em:

$<$ http://www.acessibilidadebrasil.org.br/joomla/not icias/666-instituto-benjamin-constant-lanca-oprograma-monet-gerador-de-graficos-tateis $>$. Acesso em 18 Nov. 2016.

\section{ACESSIBILIDADE BRASIL. Monet. Disponível} em:

$<$ http://www.acessibilidadebrasil.org.br/joomla/sof twares?id=685 $>$. Acesso em 18 Nov. 2016.

ANCZUROWSKI, E., inventor. Representation of Color for Blind Persons. US patente US 4650421. 1987 May. 17. Disponível em:

$<$ https://patentimages.storage.googleapis.com/pdfs/ e87b466cb039c01cb7e7/US4650421.pdf $>$. Acesso em: 18 Nov. 2016.

BATISTA, C. G.. Formação de Conceitos em
Crianças Cegas: Questões Teóricas e Implicações Educacionais. Psicologia: Teoria e Pesquisa Jan-Abr 2005, Vol. 21 n. 1, pp. 007-015. Disponível em

$<$ http://www.scielo.br/pdf/ptp/v21n1/a03v21n1.pdf >. Acesso em 15 Nov. 2016.

BAKLANOV, D., inventor. Tactile Relief Films, Decals and Stickers for Indicating Object Characteristics. US patente US 8672680 B2. 2014 Mar. 18. Disponível em:

$<$ https://docs.google.com/viewer?url=patentimages .storage.googleapis.com/pdfs/US8672680.pdf>.

Acesso em: 18 Nov. 2016.

\section{COOPER, H, L. A brief of Tactile Writing} Systems for Readers with Blindness and Visual Impairments. Disponível em: <

http://www.tsbvi.edu/seehear/spring06/history.htm >. Acesso em 13 Nov. 2016.

FRUTIGER, A. Sinais e Símbolos: Desenho, projeto e significado. $2^{\mathrm{a}}$ ed. São Paulo: Martins Fontes, 2007.

GIBSON, J, J. The senses considered as perceptual systems. Oxford, England: Houghton Mifflin. 1966 .pp.

\section{GIBSON, J, J. Psychological Review:} observations on active touch. Vol. $69, \mathrm{n}^{\circ} 6$. Cornell University, England. Nov. 1962.

Disponível em:

$<$ http://wexler.free.fr/library/files/gibson\%20(1962 \%20observations\%20on\%20active\%20touch.pdf $>$ . Acesso em: 16 Nov. 2016.

GOMES FILHO, J. Gestalt do objeto: sistema de leitura visual. $9^{a}$ ed. São Paulo: Escrituras Editora, 2009.

IBC - Instituto Benjamin Constant. Disponível em: $<$ http://www.ibc.gov.br/?itemid=10235>. Acesso em: 27 Jan. 2016.

KEPES, G. Module, proportion, symmetry, rhythm. Nova York: George Brasiller, 1966.

LAPLANE, A. L. F.; BATISTA, C. G. (2003). Um
Realização:

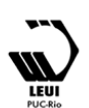




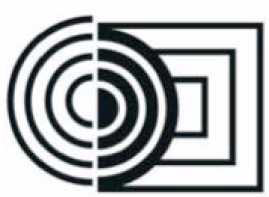

estudo das concepções de professores de ensino fundamental e médio sobre a aquisição de conceitos, aprendizagem e deficiência visual

[Resumo]. Associação Brasileira de Pesquisadores em Educação Especial (Org.), Anais do I Congresso Brasileiro de Educação Especial, IX Ciclo de Estudos sobre Deficiência Mental, (pp. 14-15). São Carlos: UFSCar. Disponível em: $<$ http://www.nutes.ufrj.br/abrapec/viiienpec/resum os/R0456-1.pdf> . Acesso em 15 Nov. 2016.

MCCALL, S.; MCLINDEN, M.. Accessing The National Literacy Strategy: The use of Moon with Children in the United Kingdom with a Visual Impairment and Additional Learning Difficulties. The British Journal of Visual Impairment, n.19, p. 7-16, 2001.

MINARDI, M. J., inventor; Touch Books, Inc., cessionário. Tactile symbols for color recognition. US patente US 5286204 A. 1994 Fev. 15. Disponível em:

$<$ https://www.google.com/patents/US5286204>. Acesso em: 18 Nov. 2016.

NOGUEIRA, F. S. A. P., inventor; Faculdade de Arquitectura, cessionário. Colour code for visually impaired people. WIPO patente WO 2013137757 A1. 2013 Set. 19. Disponível em: $<$ https://www.google.com/patents/WO2013137757 A1?cl=en>. Acesso em: 18 Nov. 2016.

OCHAITA, E.; ROSA, A. Percepção, ação e conhecimento nas crianças cegas. Disponível em: $<$ http://www.diversidadeemcena.net/artigo03.htm $>$ . Acesso em 09 Nov. 2016.

RNIB - Royal National Institute of Blind

People. Disponível em: <

http://www.rnib.org.uk/braille-and-moon-tactilecodes/moon>. Acesso em: 06 Nov. 2016.

THOMAZI, P. T. A contribuição dos objetos de aprendizagem para o ensino da teoria da cor na educação a distância. Revista Intersaberes, vol. 9, n.17, p. 81-97, jan. - jun. 2014, ISSN 1809-7286. Disponível em:

$<$ http://uninter.com/intersaberes/index.php/revista/ article/download/506/371>. Acesso em: 20 Nov.
2016 .

VANKRINKELVELDT, M., inventor; Hyper Tactile Colour Code ASBL, cessionário. Tactile symbols for colour recognition by blind or visually impaired persons. EP patente EP1318494 A1. 2003 Jun. 11. Disponível em:

$<$ https://www.google.com/patents/EP1318494A1?c $\mathrm{l}=\mathrm{en} \& \mathrm{hl}=\mathrm{pt}-\mathrm{BR}>$. Acesso em: 18 Nov. 2016.

\section{Agradecimentos}

Esse trabalho foi realizado durante o mestrado em Design pela Universidade do Estado de Santa Catarina/UDESC financiado com uma bolsa de estudos fornecida pela CAPES - Coordenação de Aperfeiçoamento de Pessoal de Nível Superior vinculada ao Ministério da Educação (MEC) do Brasil. 